\title{
The CSR-Quality Trade-Off: When can Corporate Social Responsibility and Corporate Ability Compensate Each Other?
}

\author{
Guido Berens \\ Cees B. M. van Riel \\ Johan van Rekom
}

\begin{abstract}
This paper investigates under what conditions a good corporate social responsibility (CSR) can compensate for a relatively poor corporate ability (CA) (quality), and vice versa. The authors conducted an experiment among business administration students, in which information about a financial services company's CA and CSR was provided. Participants indicated their preferences for the company's products, stocks, and jobs. The results show that for stock and job preferences, a
\end{abstract}

Guido Berens is Assistant Professor of Corporate Communication at Rotterdam School of Management, Erasmus University Rotterdam, the Netherlands. His research interests include corporate branding, corporate social responsibility, and reputation management. His research has been published in the Journal of Marketing and the Corporate Reputation Review, as well as in several international books.

Cees B. M. van Riel is Professor of Corporate Communication at the Rotterdam School of Management, Erasmus University Rotterdam, the Netherlands. His research interests include organizational identity, reputation management, and corporate branding. He is the author of several books, and his research has appeared in the Academy of Management Journal, Journal of Management Studies, and Journal of Marketing, among others. He is Editor-in-Chief of the Corporate Reputation Review, and has been working as a consultant for many large international companies in the last 15 years.

Johan van Rekom is Assistant Professor at the Rotterdam School of Management at the Erasmus University, Rotterdam, the Netherlands, where he also received his PhD. His research interests include organizational identity, the effects of organizational identity on the motivation of organization members, cognitive structures at the individual and at the organizational level, and the essence of brands. His research has appeared in the Journal of Management Studies and the European Journal of Marketing, among others. poor CA can be compensated by a good CSR. For product preferences, a poor CA could not be compensated by a good CSR, at least when people thought that CA is personally relevant to them. Furthermore, a poor CSR could be compensated by a good CA for product, stocks, and job preferences.

KEY WORDS: applicant attitudes, consumer attitudes, corporate ability, corporate social responsibility, investor attitudes, personal relevance, trade-offs

\section{Introduction}

Doing good has become increasingly important in the last decades. Developments in this area have led to an ever-increasing attention to what became to be coined as CSR, i.e., corporate social responsibility. Following del Mar Garcia de los Salmones et al. (2005, p. 369), we define CSR as: "the moral obligations that maximize the positive impact of the firm on its social environment and minimize the negative impact." It includes such issues as environmental protection, relations with local communities, working conditions, and donations to charities. Business benefits, while not the only motivation for companies to engage in actions aimed at CSR, do strengthen the case for engaging in such actions.

While previous studies have sometimes provided mixed results, in general they show that CSR actions have a positive influence on the preferences of consumers (e.g., Brown and Dacin, 1997; del Mar Garcia de los Salmones et al., 2005), investors (see Orlitzky et al., 2003), and job applicants (e.g., Backhaus et al., 2002; Greening and Turban, 2000). In addition, 
previous research has provided insights into the conditions under which CSR has a positive influence. For example, several studies have shown that certain types of CSR have more influence on the preferences of different stakeholders than others (Greening and Turban, 2000; Hillman and Keim, 2001; Sen and Bhattacharya, 2001). In addition, Madrigal (2000) found that the influence of CSR on consumer product preferences is especially strong when people perceive the product to fit well with the company. Similarly, Goll and Rasheed (2004) established that the influence of CSR on investor preferences is especially strong in dynamic and munificent business environments.

However, corporate resources, in terms of time, money and managerial attention are scarce. This problem of scarcity is aggravated by the fact that most firms compete in different markets simultaneously, i.e., in consumer markets for selling their products, in labor markets for attracting the best personnel and in financial markets for attracting investors. Managers thus have to make well-underpinned allocation decisions, carefully considering the added value of each dollar they invest in each of their business activities. Instead of investing in a good CSR record, the resources may be needed for sustaining and developing the abilities the company needs to compete in the market and to deliver the appropriate quality. Therefore, a trade-off is often needed, even if managers might wish to have an excellent reputation on both aspects. It is important to know how investments in corporate ability (CA) versus CSR pay off in product, job and financial markets, respectively.

Previous research did not make clear whether, and when, a favorable CSR can compensate for weaknesses in CA. CA refers to a "company's expertise in producing and delivering its outputs" (Brown and Dacin, 1997, p. 68). It includes not only product quality, but also attributes like innovativeness, customer orientation, and others. Suppose a customer facing a purchase decision can choose between the products of two companies. One has excellent products and services, but also has a reputation for polluting the environment, mistreating its employees, and disregarding community interests. The other company's products and services are of below average quality, but it has an excellent track record regarding environmental impact, employee treatment, and community relations. Which company will the person choose, and why? Will the company with a better CSR record be chosen, even though it has a relatively low quality? Our research question, therefore, is: are CA and CSR stand-alone business activities, or are there synergies between them, such that lagging performance in one of them cannot be compensated by the other? In particular, we want to find out under which conditions favorable information on a company's CA and favorable information on a company's CSR are both necessary to establish favorable preferences, and under which conditions favorable information on one aspect can compensate for unfavorable information on the other aspect. Following the focus of previous studies on the benefits of CSR, we focus on people's reactions to a company's products, stocks, and job offers.

\section{The likelihood of stakeholders trading off CSR and CA}

Several authors in cognitive psychology have looked at the more general question of whether positive attributes can compensate for negative attributes. Research on decision-making has demonstrated that people often do not trade off all attributes of all decision options against each other, but employ a diversity of heuristics (see Bettman et al., 1998; Dawes, 1964). One such heuristic is to look at only the best attributes an option has. This is called "disjunctive" decision-making. Another heuristic is to look only at the worst attributes, which is called "conjunctive" decision-making. In the latter strategy, a positive attribute cannot compensate for a negative attribute. Furthermore, research has shown that in forming an overall evaluation, negative and extreme attributes tend to weigh more heavily than positive and moderate attributes (Anderson, 1981; Baumeister et al., 2001; Lynch, 1979). These findings have been called "negativity effect" and "extremity effect," respectively. The presence of a negativity effect suggests that positive attributes cannot fully compensate for negative attributes, consistent with conjunctive decision-making. Folkes and Kamins (1999) showed that "negativity effects" occur both for CSR and for CA. Their results demonstrate that when a company acts unethically, the quality of its product (i.e., CA) does not influence people's attitudes toward the firm. Similarly, when a company has an inferior product, acting 
prosocially does not influence people's attitudes. Similar results have been obtained by Handelman and Arnold (1999) and by Barone et al. (2000). These results suggest that consumers perceive both CA and CSR to be necessary attributes of a company, so that a good CA record cannot compensate for a poor CSR record, and vice versa.

However, these previous studies have not investigated under what conditions these effects are more likely to occur. It seems likely that in some situations, a good CA can compensate for a relatively poor CSR, and similarly, that in some situations, a good CSR can compensate for a poor CA. Clearly, in many cases people continue to buy from companies with a publicly known poor CSR record because they like their products (e.g., Carrigan and Attalla, 2001). For them, the product's good quality offsets the poor CSR. Similarly, some idealistic people may continue to buy from companies with a good CSR record despite a relatively poor quality, in which case a good CSR offsets a poor quality.

Some research in cognitive psychology has focussed on the conditions facilitating negativity effects in general (Baron and Spranca, 1997; Baumeister et al., 2001; Luce et al., 1999; Tetlock et al., 2000). These studies show that for some attributes, negative information threatens a person's personal goals or values. When an object is rated poorly on such attributes, this cannot be compensated by other attributes. We propose here that these results shed some light on this issue of when CA and CSR can compensate each other in people's overall evaluation of companies. Particularly, we propose that the degree to which CA or CSR information presents a potential threat to a person's goals predicts whether or not unfavorable CA and CSR information can be compensated.

\section{Hypotheses development}

The research model used in this study is shown in Figure 1. Consistent with previous research (e.g., Greening and Turban, 2000; Hillman and Keim, 2001; Sen and Bhattacharya, 2001), we expect that information about a company's CA and CSR has a significant positive influence on people's behavioral intentions regarding the company's products, stocks, and jobs.

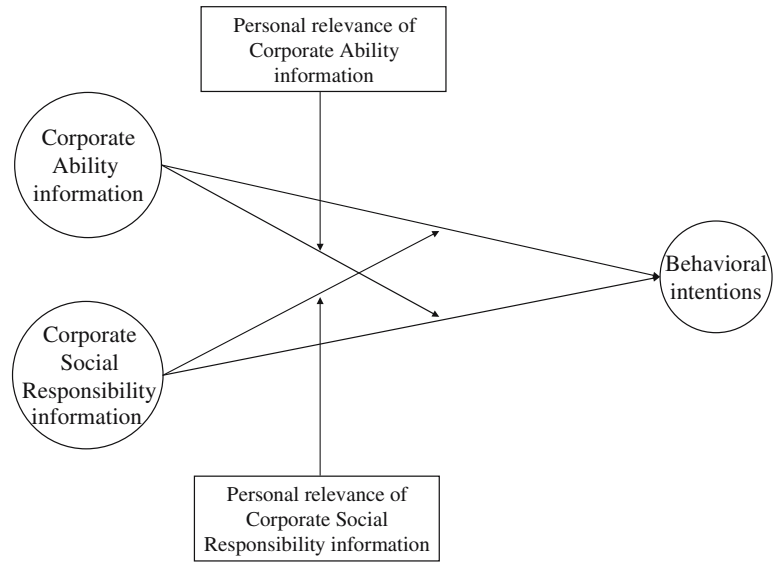

Figure 1. The effect of personal relevance on the interactive effects of Corporate Ability and Corporate Social Responsibility information on behavioral intentions toward products, stocks, and jobs.

Following previous studies which examined the question of whether CA and CSR can compensate each other (Barone et al., 2000; Folkes and Kamins, 1999; Handelman and Arnold, 1999), we expect that on average, favorable CSR information cannot compensate for unfavorable CA information, and vice versa, that favorable CA information cannot compensate for unfavorable CSR information. As Billings and Marcus (1983) point out, non-compensatory processing may be investigated by examining interactions between attributes. A significant positive interaction would indicate that when one attribute is poor, other attributes have less effect than when the attribute is good. We expect $C A$ to positively moderate the effect of CSR on people's intentions, and CSR to positively moderate the effect of CA on people's intentions. The first hypothesis is therefore:

$H_{1 a}$ : The weaker an organization's performance on CA, the weaker the relationship between its CSR performance and a person's intention to do business with that organization.

$H_{1 b}$ : The weaker an organization's performance on CSR, the weaker the relationship between its CA performance and a person's intention to do business with that organization.

But under what conditions can we expect that such an effect is most likely to occur? As noted above, 
research in the psychology of decision-making has shown that some attributes of objects may pose threats to important personal goals (e.g., good health, survival, happiness) when they are unfavorable (Baron and Spranca, 1997; Luce et al., 1999; Tetlock et al., 2000).

When such goals are threatened, these attributes become associated with potential negative emotions (Lazarus, 1991). As a way to cope with these emotions, people may then resist trading off the attributes against other attributes (Jones and Johnson, 1973; Luce et al., 1999). For example, most consumers would prefer a safe car to an unsafe car, no matter how much cheaper the unsafe car is. Research has also shown that this perceived relevance to important goals is more than "merely" an evaluation of attribute importance (Luce et al., 1999, 2000). For example, in choosing a car, a person may judge safety to be equally important as style or price, but still find an unsafe car to far be more personally threatening than an ugly or expensive car.

Following this reasoning, we can expect that when information on a company's CA or CSR is personally relevant to people, i.e., when this information is relevant to their important (high-ranking) goals, people will not consider entering into a relationship with a company that has a poor CA or CSR record, no matter how favorable other attributes are. However, it still remains to be seen whether CA and CSR information really can be directly personally relevant to people. In the next section, we discuss situations in which information about a company's CA could be relevant to people's important personal goals, so that they would refuse to compensate a poor CA. Next, we consider situations in which information on a company's CSR may be relevant to people's important goals.

\section{The personal relevance of $C A$ information}

In some situations, information on a company's CA could be personally relevant to people in the context of deciding to buy a product or a company's stocks, or in deciding whether to apply for a certain job. For example, when a customer is planning to invest a large sum of money in a fund, information on an investment company's CA can be relevant to the customer's goal of making money, or avoiding losing money. The customer may reason that doing business with a low-CA company will increase the probability of losing money (cf. Gürhan-Canli and Batra, 2004). Similarly, an investor may reason that a company's CA will likely impact the company's financial performance, and therefore the returns he or she will get from a company's stocks. Finally, because of this link with a company's financial performance, a company's CA may impact the security of a job at the company, which may also be an important goal to people when they have to decide about accepting a job offer. In addition, a company's CA could influence the self-esteem that a person derives from working at the company (Greening and Turban, 2000).

When information about a company's CA is linked to the personal goals that people want to achieve in a certain situation, it is likely that a good CSR record cannot compensate a poor CA. For example, in such a case, a person will not consider investing in a fund from a company with a poor CA, no matter how well it performs in terms of CSR.

Conversely, people may sometimes perceive CA information to be less personally relevant. For example, people may believe that the performance of an investment fund depends on the performance of the market as a whole, rather than on the expertise of the investment company. Or they may find the quality of the product itself to be relatively unimportant to fulfill their goals. This would likely be the case for typical "low-involvement" products, such as fast moving consumer goods. Similarly, some people may not think that working for a company with a poor CA would endanger their job security or self-esteem. For example, this may be the case for some companies in the public sector, in which job security does not directly depend on the company's performance. In such cases, CA information should not be relevant to predict whether or not an important goal will be fulfilled. Then, we can expect that information about a company's CSR can have a positive effect on intentions, even when information on CA is unfavorable. Thus, the interaction between $C A$ and CSR will be stronger when CA is perceived as personally relevant, than when $C A$ is not perceived as personally relevant. We therefore formulate the following hypothesis. 
$H_{2 a}$ : The higher the personal relevance of CA, the more seriously a weak organizational CA performance undermines the relationship between performance on CSR and that person's intention to do business with that organization.

\section{The personal relevance of CSR information}

Information on a company's CSR may also be relevant to people's goals in the context of choosing a product, stock, or job. For example, a company's reputation for environmental friendliness may be relevant for consumers to evaluate the quality of a specific environmentally friendly product (Madrigal, 2000). Similarly, a company's reputation for CSR may be relevant for investors who have to decide whether or not to buy a company's stocks, since they may reason that the quality of a company's relationships with its stakeholders is likely to impact its performance (Epstein and Schnietz, 2002). Job applicants' perceptions of the way a company treats its employees (a type of CSR) are likely to be relevant for the satisfaction they expect from accepting a job offer from the company (Schwoerer and Rosen, 1989). In addition, for decisions regarding products, stocks, as well as job offers, paying attention to CSR may be relevant for people in order to live their lives according to their moral values (Frank, 1996). Furthermore, entering into a relationship with a socially responsible company may be a way to express one's personal identity (Sen and Bhattacharya, 2001). When CSR is relevant to important goals, we can expect that a favorable CA cannot compensate for an unfavorable CSR.

Conversely, some people may not perceive CSR to be relevant to their goals in a specific situation. For example, some people may think that a company's CSR activities are irrelevant in predicting the performance of the company's stock. Or they may not perceive the type of CSR activities that a company displays to be relevant to their values or personal identities. When CSR is not relevant to people's important goals, we can expect that a good CA can compensate for a poor CSR. In other words, the interaction between CA and CSR will be stronger when CSR is perceived as personally relevant, than when CSR is not perceived as personally relevant. We therefore hypothesize, in analogy to hypothesis $2 \mathrm{a}$ :
$H_{2 b}$ : The higher the personal relevance of CSR, the more seriously a weak organizational CSR undermines the relationship between performance on CA and that person's intention to do business with that organization.

\section{Method}

To test the hypotheses, we conducted an Internetbased experiment. In this experiment, we manipulated CA and CSR information between subjects in the form of scenarios ${ }^{1}$. These scenarios were about a financial services provider offering investment funds. The reason for this choice was that, on the one hand, these types of products can have clear negative consequences that are hard to avoid, but that on the other hand, some people may see CA as irrelevant to these consequences ${ }^{2}$. Therefore, it seems likely that there would be sufficient variation in the degree to which respondents perceived the company's CA as personally relevant in the context of evaluating a product.

\section{Materials}

We provided respondents with descriptions of a fictitious Canadian company called "Groupe Lejeune." We chose a Canadian company because the respondents used in this study (Dutch students) could be assumed to be relatively unfamiliar with Canadian companies in general, and with Canadian banks in particular. This was necessary in order to make sure respondents would regard the materials as realistic. In addition, most people in the Netherlands probably know that Canada is a developed Western country, but are still relatively unfamiliar with it, and therefore do not have strong opinions regarding the country. Therefore, we could assume that Canada as the country of origin of a bank would likely neither evoke very negative nor very positive associations among our respondents. The company's CA was operationalized as the overall quality of this company's products and services (high and low), in the form of Consumer Reports type tables regarding two different services: advice about loans and car insurance. CSR was operationalized as the degree to which the company "screens" companies and other entities it invests in on their ethical conduct (to a high degree versus not at 
all). A specific example was discussed regarding the company's investments in rainforest logging companies. To ensure sufficient realism of the CA and CSR manipulations, we deliberately chose to avoid extreme levels of either one. Thus, the company's service quality was portrayed as one of the weaker in the "poor CA" condition, and as one of the better in the "high CA" condition. Similarly, the type of CSR that was discussed was not such that most people would perceive it as extremely negative or extremely positive. A qualitative pretest among four respondents (business administration students) showed that they perceived the materials as credible. Some of these respondents also indicated that the questionnaire was rather long. All experimental materials are provided in Appendix A.

In addition to CA and CSR, we manipulated the type of preference within subjects, by giving information about a high risk investment fund (an "Asian Tigers Fund") marketed by the company, a job offer by the company (a traineeship), and the company's own stocks. The dependent variables are people's behavioral intentions regarding these three objects. The result is a $2(\mathrm{CA}) \times 2(\mathrm{CSR}) \times 3$ (preference type) mixed design. The order of all manipulations was randomized between subjects, to avoid order effects.

\section{Respondents}

A total of 112 undergraduate business administration students participated in the study. Students were recruited via their enrollment in specific courses, and assigned randomly to one of the experimental conditions. We think that the use of a student sample is justified for our research, first, because the goal of an experiment is to maximize internal validity, rather than external validity. While students might not be representative of consumers in general, our primary aim is to establish whether the hypothesized effects occur at all, leaving the question for whom these effects apply for future studies. Second, we think that the stimuli we provided are likely to be relevant to business administration students. These students are likely to have some interest in traineeships and financial investments. On the other hand, they are unlikely to own the kind of money needed for a substantial investment. To circumvent this problem, we asked the respondents to imagine they had unexpectedly received a large amount of money $(€ 100,000)$ and had already decided to invest this money in an Asian investment fund or in a portfolio of stocks, respectively.

\section{Procedure}

An online (HTML) questionnaire was used for the experiment. Subjects were instructed to follow a link to a web page, on which the questionnaire could be found. Care was taken to ensure that the questionnaire would run smoothly and would look identical through any type of computer and web browser. The descriptions of the company's CA and CSR were presented first, followed by descriptions of the fund, stocks, and job. For each of these objects, questions were asked about the personal relevance of CA and CSR information in the context of this type of preference, as well as questions about behavioral intentions. After this, manipulation check measures were taken regarding the favorability of respondents' CA and CSR associations with the company. The questionnaire concluded with inquiries into subjects' expertise regarding investing, as well as their age and gender.

\section{Measures}

All measures and their reliabilities can be found in Appendix B. All dependent, independent, and moderator variables were measured on 7-point semantic differential scales. Descriptive statistics for all composite scales for each experimental cell are provided in Table I, and correlations between the main variables for each of the three types of preference are provided in Table II.

\section{Dependent measures}

We measured people's behavioral intentions regarding the fund, stocks, and job on two semantic differential scales for the fund and the stocks, and on three scales for the job offer (cf. Schwoerer and Rosen, 1989).

\section{Moderator measures}

To measure the degree to which the information on the company's CA and CSR was personally 
TABLE I

Descriptive statistics for each experimental cell

\begin{tabular}{|c|c|c|c|c|c|c|}
\hline & \multicolumn{2}{|c|}{ Fund } & \multicolumn{2}{|c|}{ Stocks } & \multicolumn{2}{|c|}{ Job } \\
\hline & Mean & $\mathrm{SD}$ & Mean & SD & Mean & SD \\
\hline \multicolumn{7}{|l|}{ Low corporate ability } \\
\hline \multicolumn{7}{|l|}{ Low corporate social responsibility } \\
\hline Perceived corporate ability & 3.67 & 1.12 & 3.67 & 1.12 & 3.67 & 1.12 \\
\hline Perceived corporate social responsibility & 2.39 & 1.04 & 2.39 & 1.04 & 2.39 & 1.04 \\
\hline Behavioral intention & 3.15 & 1.36 & 2.46 & 1.19 & 2.46 & 1.19 \\
\hline Personal relevance of corporate ability information & 3.98 & 1.43 & 4.85 & 1.19 & 4.54 & 1.27 \\
\hline Personal relevance of corporate social responsibility information & 4.24 & 1.45 & 4.80 & 1.58 & 4.87 & 1.67 \\
\hline \multicolumn{7}{|l|}{ High corporate social responsibility } \\
\hline Perceived corporate ability & 3.57 & 1.11 & 3.57 & 1.11 & 3.57 & 1.11 \\
\hline Perceived corporate social responsibility & 5.30 & 0.82 & 5.30 & 0.82 & 5.30 & 0.82 \\
\hline Behavioral intention & 3.52 & 1.35 & 3.11 & 1.18 & 3.93 & 1.18 \\
\hline Personal relevance of corporate ability information & 3.96 & 1.75 & 4.76 & 1.10 & 4.74 & 1.42 \\
\hline Personal relevance of corporate social responsibility information & 3.80 & 1.58 & 4.44 & 1.70 & 4.83 & 1.52 \\
\hline \multicolumn{7}{|l|}{ High corporate ability } \\
\hline \multicolumn{7}{|l|}{ Low corporate social responsibility } \\
\hline Perceived corporate ability & 5.63 & 0.67 & 5.63 & 0.67 & 5.63 & 0.67 \\
\hline Perceived corporate social responsibility & 2.69 & 1.25 & 2.69 & 1.25 & 2.69 & 1.25 \\
\hline Behavioral intention & 4.23 & 1.41 & 3.78 & 1.41 & 4.25 & 1.19 \\
\hline Personal relevance of corporate ability information & 3.87 & 1.41 & 4.32 & 1.40 & 4.48 & 1.31 \\
\hline Personal relevance of corporate social responsibility information & 4.11 & 1.50 & 4.45 & 1.48 & 4.79 & 1.16 \\
\hline \multicolumn{7}{|l|}{ High corporate social responsibility } \\
\hline Perceived corporate ability & 5.29 & 0.77 & 5.29 & 0.77 & 5.29 & 0.77 \\
\hline Perceived corporate social responsibility & 5.40 & 1.11 & 5.40 & 1.11 & 5.40 & 1.11 \\
\hline Behavioral intention & 4.38 & 1.15 & 4.57 & 1.12 & 4.24 & 1.12 \\
\hline Personal relevance of corporate ability information & 4.00 & 1.36 & 4.69 & 1.24 & 4.67 & 0.99 \\
\hline Personal relevance of corporate social responsibility information & 3.98 & 1.49 & 4.55 & 1.14 & 4.74 & 1.29 \\
\hline
\end{tabular}

relevant to respondents in the case of the investment fund, the stocks, and the jobs, we adapted measures of perceived diagnosticity, asking about the perceived usefulness of a specific piece of information for a specific judgment (e.g., Aaker and Sengupta, 2000). Specifically, we asked subjects to evaluate the perceived usefulness of the information on $\mathrm{CA}$ and the information on CSR for judging possible negative consequences of accepting the company's product, stocks, and job offer. To make clear what we meant by "negative consequences," we first asked the respondents about several potential risks associated with the product: functional, financial, psycho- logical, social, and overall risk (Jacoby and Kaplan, 1972). ${ }^{3}$

Manipulation check measures

Manipulation check measures for CA were taken from the "expertise" dimension of Newell and Goldsmith's (2001) corporate credibility scale. This dimension consists of four items, but two of those seem to deal more with the length of a company's experience than with actual expertise. We therefore only used the two items directly related to perceived expertise. Two items dealing with the company's perceived ethical behavior and social responsibility served as a manipulation check for CSR. 
TABLE II

Correlations

\begin{tabular}{|c|c|c|c|c|}
\hline & $\begin{array}{l}\text { Corporate } \\
\text { ability }\end{array}$ & $\begin{array}{l}\text { Corporate } \\
\text { social } \\
\text { responsibility }\end{array}$ & Intention & $\begin{array}{l}\text { Personal relevance } \\
\text { of corporate ability }\end{array}$ \\
\hline \multicolumn{5}{|l|}{ Fund } \\
\hline Corporate social responsibility & -0.05 & & & \\
\hline Behavioral intention & 0.34 & 0.07 & & \\
\hline Personal relevance of corporate ability & -0.01 & 0.02 & -0.21 & \\
\hline Personal relevance of corporate social responsibility & 0.02 & -0.09 & -0.15 & 0.38 \\
\hline \multicolumn{5}{|l|}{ Stocks } \\
\hline Corporate social responsibility & -0.05 & & & \\
\hline Behavioral intention & 0.47 & 0.23 & & \\
\hline Personal relevance of corporate ability & -0.12 & 0.07 & 0.05 & \\
\hline Personal relevance of corporate social responsibility & -0.04 & -0.04 & 0.16 & 0.46 \\
\hline \multicolumn{5}{|l|}{ Job } \\
\hline Corporate social responsibility & -0.05 & & & \\
\hline Behavioral intention & 0.15 & 0.01 & & \\
\hline Personal relevance of corporate ability & -0.03 & 0.08 & 0.09 & \\
\hline Personal relevance of corporate social responsibility & -0.03 & -0.01 & 0.14 & 0.39 \\
\hline
\end{tabular}

\section{Scale validation}

Before collecting the experimental data, we conducted a qualitative pretest of the questionnaire, in which people filled it out and commented on any unclarities that they encountered. This is especially important for Internet questionnaires, as respondents are not able to ask questions while filling them in (Evans and Mathur, 2005). This pretest resulted in a few changes in the wording of the questions and in the instructions. An additional pretest showed that the wording of the final questionnaire was sufficiently clear to respondents.

After the experiment, we conducted a quantitative scale validation process. We did this separately for the fund, shares, and job evaluations. In addition, to control for the effect of the manipulations on the correlations between the measures, we used the residuals obtained from ANOVAs estimating the influence of the experimental conditions on all measured variables (Voss and Parasuraman, 2003). First, we conducted reliability analyses to see whether any items did not correlate highly (above 0.4) with the scales to which they belonged. This was not the case for any of the measures. Second, we conducted a confirmatory factor analysis of all measures, to assess whether all items loaded significantly on their respective scales, and not on other scales. The factor model showed adequate fit for all three types of preference.

\section{Analysis}

The data were analyzed using hierarchical moderated regression models with dummy variables representing the CA and CSR conditions, and the measures of the personal relevance of CA and CSR information as moderators. We analyzed respondents' evaluations of the three types of preference (fund, stocks, and job) separately. In addition, following the regression procedure described by Judd et al. (1996), we tested whether any of the effects differed significantly between the fund, stocks, and job. This was done to avoid capitalizing on chance when evaluating the same model for three different types of preference.

\section{Results}

Before discussing the results of the regression models, we investigate whether the manipulations of CA 
TABLE III

Regression results ${ }^{\mathrm{a}}$

\begin{tabular}{|c|c|c|c|c|c|c|c|}
\hline \multirow[t]{2}{*}{ Model } & & \multicolumn{2}{|c|}{ Investment fund } & \multicolumn{2}{|c|}{ Stocks } & \multicolumn{2}{|c|}{ Job } \\
\hline & & $B$ & $(t)$ & $B$ & $(t)$ & $B$ & $(t)$ \\
\hline \multirow[t]{6}{*}{ Main effects } & (Constant) & 4.19 & $(9.00)$ & 1.54 & $(2.91)$ & 3.11 & $(5.55)$ \\
\hline & $\mathrm{CA}$ & 0.96 & $(3.88)$ & 1.42 & $(6.06)$ & 0.40 & $(1.68)$ \\
\hline & CSR & 0.24 & $(0.96)$ & 0.75 & $(3.20)$ & 0.03 & $(0.15)$ \\
\hline & Personal relevance of CA & -0.16 & $(-1.77)$ & 0.00 & $(0.05)$ & 0.04 & $(0.36)$ \\
\hline & Personal relevance of CSR & -0.08 & $(-0.91)$ & 0.18 & $(2.06)$ & 0.12 & $(1.24)$ \\
\hline & Adjusted $R^{2}$ & & 0.14 & & 0.30 & & 0.01 \\
\hline \multirow[t]{11}{*}{ Two-way } & (Constant) & 5.56 & $(7.26)$ & 4.12 & $(4.39)$ & 3.10 & (3.66) \\
\hline & $\mathrm{CA}$ & 1.27 & $(3.54)$ & 1.20 & $(3.71)$ & 0.49 & $(1.48)$ \\
\hline & CSR & 0.33 & $(0.89)$ & 0.64 & $(1.94)$ & 0.11 & $(0.34)$ \\
\hline & Personal relevance of CA & -0.32 & $(-1.65)$ & -0.12 & $(-0.68)$ & 0.20 & $(0.99)$ \\
\hline & Personal relevance of CSR & -0.27 & $(-1.39)$ & -0.22 & $(-1.57)$ & -0.04 & $(-0.26)$ \\
\hline & $\mathrm{CA} \times \mathrm{CSR}$ & -0.10 & $(-0.21)$ & 0.09 & $(0.20)$ & -0.19 & $(-0.42)$ \\
\hline & $\mathrm{CA} \times$ Personal relevance CA & 0.31 & $(1.60)$ & 0.23 & $(1.13)$ & 0.23 & $(1.07)$ \\
\hline & $\mathrm{CA} \times$ Personal relevance CSR & 0.29 & $(1.54)$ & 0.29 & $(1.67)$ & -0.11 & $(-0.60)$ \\
\hline & $\mathrm{CSR} \times$ Personal relevance CA & 0.08 & $(0.41)$ & -0.20 & $(-0.96)$ & -0.69 & $(-3.28)$ \\
\hline & CSR $\times$ Personal relevance CSR & 0.09 & $(0.48)$ & 0.66 & $(3.79)$ & 0.54 & $(3.01)$ \\
\hline & Adjusted $R^{2}$ & & 0.18 & & 0.38 & & 0.13 \\
\hline \multirow[t]{13}{*}{ Three-way } & (Constant) & 4.92 & $(5.80)$ & 4.10 & $(3.63)$ & 2.77 & $(2.91)$ \\
\hline & CA & 1.03 & $(2.87)$ & 1.20 & (3.64) & 0.50 & (1.48) \\
\hline & CSR & 0.17 & $(0.45)$ & 0.61 & $(1.76)$ & 0.13 & $(0.38)$ \\
\hline & Personal relevance of CA & 0.15 & $(0.56)$ & -0.17 & $(-0.78)$ & 0.31 & $(1.25)$ \\
\hline & Personal relevance of CSR & -0.56 & $(-2.10)$ & -0.17 & $(-1.09)$ & -0.08 & $(-0.43)$ \\
\hline & $\mathrm{CA} \times \mathrm{CSR}$ & 0.26 & $(0.51)$ & 0.13 & $(0.28)$ & -0.25 & $(-0.52)$ \\
\hline & CA × Personal relevance CA & -0.36 & $(-1.14)$ & 0.31 & (1.16) & 0.06 & $(0.18)$ \\
\hline & $\mathrm{CA} \times$ Personal relevance CSR & 0.58 & $(1.91)$ & 0.19 & $(0.84)$ & -0.09 & $(-0.34)$ \\
\hline & CSR $\times$ Personal relevance CA & -0.57 & $(-1.83)$ & -0.08 & $(-0.25)$ & -0.87 & $(-2.77)$ \\
\hline & CSR $\times$ Personal relevance CSR & 0.44 & $(1.37)$ & 0.56 & $(2.48)$ & 0.60 & $(2.31)$ \\
\hline & $\mathrm{CA} \times \mathrm{CSR} \times$ Personal relevance CA & 1.06 & $(2.72)$ & -0.23 & $(-0.55)$ & 0.35 & $(0.82)$ \\
\hline & $\mathrm{CA} \times \mathrm{CSR} \times$ Personal relevance CSR & -0.35 & $(-0.90)$ & 0.26 & $(0.73)$ & -0.06 & $(-0.15)$ \\
\hline & Adjusted $R^{2}$ & & 0.22 & & 0.37 & & 0.12 \\
\hline
\end{tabular}

${ }^{a}$ All coefficients are unstandardized regression coefficients. $T$-values are provided in parentheses.

and CSR information had the intended effects on people's evaluations of these attributes. The results of $2 \times 2$ ANOVAs showed that the manipulation of CA information had a significant positive influence on the favorability of CA associations $\left(F_{(1,}\right.$ 107) $=109.00, p=0.00)$. It did not have a significant effect on the favorability of CSR associations $\left(F_{(1}\right.$, 107) $=0.93, p=0.34)$. Likewise, the manipulation of CSR information had a significant positive influence on the favorability of CSR associations $\left(F_{(1,107)}=185.70, p=0.00\right)$, and no significant effect on the favorability of CA associations $\left(F_{(1,107)}=1.51, p=0.22\right)$. Neither one of the manipulations had a significant effect on the perceived personal relevance of CA or CSR information. Therefore, respondents' perceptions of the company seem to correspond to the information we gave them.

The results of the regressions are shown in Table III. It can be seen that CA has a significant effect on people's intentions to engage in the investment fund, the company's stocks, and the 
company's job offer. CSR has a significant effect on respondents' intentions toward the company's stocks. The differences between the effects of CA and CSR on the three preference types are confirmed to some degree by the regression models testing these differences: the effect of CSR is significantly larger for the stocks than for the job $(t=1.80, p=0.08)$, and the same holds for the effect of CA $(t=2.72, p=0.01)$.

Given the results of previous studies (e.g., Backhaus et al., 2002), it is somewhat surprising that CSR has no significant influence on people's intentions toward the company's job offer. However, Table III shows that for the job, there is a significant positive interaction between CSR and the personal relevance of CSR information $(t=3.01, p=0.003)$, and a significant negative interaction between CSR and the personal relevance of CA information $(t=-3.28, p=0.001)$. These interactions show that when the information on the company's CSR is perceived as personally relevant, this CSR information does have an effect on intentions regarding the job offer $(t=2.64$, $p=0.01, \alpha=0.05)$. Similarly, when the information on the company's CA is not perceived as personally relevant, CSR information also has an effect $(t=2.72, p=0.008, \alpha=0.05)$.

Turning now to the hypotheses, we expected that the effect of CSR would depend on the level of CA, and vice versa, that the effect of CA would depend on the level of CSR $\left(\mathrm{H}_{1 \mathrm{a}}\right.$ and $\left.\mathrm{H}_{1 \mathrm{~b}}\right)$. The two-way interaction between CA and CSR, presumably indicating to what degree CA and CSR are integrated in a non-compensatory way (Billings and Marcus, 1983), is not significant in any of the models.

However, we also expected that favorable CSR information could not compensate for unfavorable CA information when this CA information was personally relevant, but that CSR could compensate for a poor CA when CA information was not personally relevant $\left(\mathrm{H}_{2 \mathrm{a}}\right)$. In agreement with this expectation, the three-way interaction between CA, CSR, and the personal relevance of the CA information is significant and positive for the fund. It is not significant for the stocks or for the job. This pattern of results is supported by the fact that the interaction is also significantly larger for the fund than for the stocks $(t=1.93, p=0.06)$.
We estimated the significance of the conditional effects composing this interaction following the procedure described by Jaccard et al. (1990). This procedure uses conservative levels of the significance level $(\alpha)$ to correct for the fact that multiple significance tests are conducted. The estimated conditional effects that compose this interaction are illustrated in Figure 2. It can be seen that when the information on CA is personally relevant, the effect of CSR information on product purchase intentions is larger when CA is favorable, than when CA is unfavorable. In this situation, CSR has a significant positive effect on purchase intentions, but only when CA is favorable $(b=1.15, t=2.08, p=0.04$, $\alpha=0.05)$. When CA is unfavorable, CSR does not have a positive effect on purchase intentions $(b=-0.67, t=-1.05, p=0.30, \alpha=0.05)$. Consistent with hypothesis 2 , this suggests that when people perceive information on CA as personally relevant, a good CSR cannot compensate for a poor CA.

On the other hand, when information on CA is not personally relevant, the opposite pattern is observed. That is, the effect of CSR is larger when CA is unfavorable $(b=1.01, t=1.88, p=0.06$, $\alpha=0.03)$, than when CA is favorable $(b=-0.29$,

High personal relevance of Corporate Ability

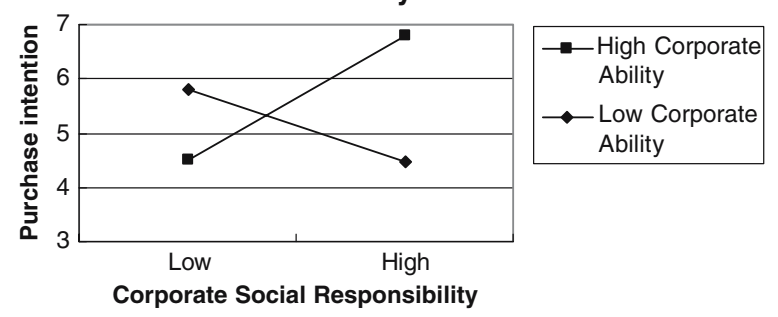

Low personal relevance of Corporate Ability

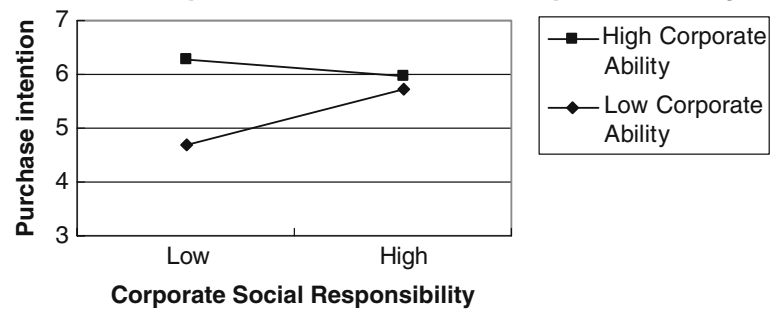

Figure 2. Conditional effects of Corporate Social Responsibility information for different levels of Corporate Ability information and the personal relevance of Corporate Ability. 
$t=-0.69, p=0.49, \alpha=0.10)$. This implies that when people do not see information on the company's CA as particularly relevant to them personally, CSR has a positive effect on purchase intentions only when the company has a relatively poor CA. Surprisingly, when the company has a relatively good CA, CSR does not have a significant effect. This is not quite as we predicted. While this pattern of results suggests that a good CSR can compensate for unfavorable CA information when the latter is not perceived as personally relevant, it also suggests that, in this situation, giving information about a good CSR does not add much value for a company that already has a good CA.

We also expected that the three-way interaction between CA, CSR, and the personal relevance of the CSR information would be significant $\left(\mathrm{H}_{2 \mathrm{~b}}\right)$. However, this is not the case. This suggests that a favorable CA can compensate for unfavorable CSR information, even when information on the company's CSR is perceived as relevant to people's personal goals.

\section{Discussion}

The results reported in this paper extend the literature on the influence of corporate social responsibility (CSR) on the preferences of stakeholders (e.g., Backhaus et al., 2002; del Mar Garcia de los Salmones et al., 2005; Orlitzky et al., 2003) by looking explicitly at the conditions under which CSR has a stronger influence. First, the results show that CSR has a different effect for different types of preferences. When people had to evaluate a company's product or job offer, CSR did not have a significant influence on their intentions regarding these offerings. On the other hand, when people had to evaluate the company's own stocks, CSR did have a significant influence. The absence of a significant effect of CSR on reactions to products and jobs could be explained by assuming that many of the respondents did not sufficiently care about the type of CSR that was discussed (i.e., environmental protection) to take it into consideration in their intentions regarding the company's products and jobs. This explanation is supported by the fact that the effect of CSR information on evaluations of the job was stronger when people perceived this information to be relevant to their goals.
Second, the results showed that when people evaluate a company's stocks or jobs, a good CSR is able to compensate for a relatively poor CA, even when people perceive the information on CA to be highly relevant to their personal goals. Therefore, for evaluating stocks and jobs, there seems to be a balance between the roles of CA and CSR associations. Having a good CA is not absolutely necessary for people to establish favorable preferences, so that there is more room for CSR information to play a role.

For evaluations of a company's products, the situation is different. Here, a good CSR may sometimes, but not always, compensate for a poor CA. When information on a company's CA was personally important to people, e.g., when they thought that doing business with a company with a poor CA would lead to the possibility of losing a lot of money, a good CSR could not compensate for a poor CA. In such a case, CSR only had a significant effect on purchase intentions when CA was high, but not when CA was low. This suggests that in this case, having a good CA is a necessary precondition for a positive reaction to occur.

When information on CA was not personally relevant to people in the context of evaluating a product, a favorable CSR was able to compensate for a poor CA. In fact, in this case CSR had a stronger effect on behavioral intentions when CA was poor, than when CA was good. This suggests that, when CA is high, this is sufficient - under these circumstances, higher performance on CSR does not add to the intention to engage in business with the organization. However, when CA is low, a high CSR could suggest to stakeholders that the organization at least makes a serious issue of societal matters, and this may suggest a certain degree of conscientiousness. Such an organization is always still a better partner to do business with than an organization that is low on both CA and CSR. This effect only comes about with people to whom CA has low personal relevance. For people to whom CA is highly personally relevant, what the organization can do is too important to allow for compensation. Translating these findings to the practice of day-to-day business, the high personalrelevance respondents may correspond to customers and potential customers, who have a stake in the organization properly performing on its abilities, and 
the low personal-relevance respondents may correspond to the more general public.

Personal relevance of CSR performance makes less of a difference, not to say none at all. For none of the three preferences (for the investment fund, for the stocks, and for the job), the personal relevance of CSR information determined whether favorable information on a company's CA could compensate for a poor CSR. A good CA was able to compensate for an unfavorable CSR, even when people thought that negative personal consequences might result from a relationship with a company that is relatively poor on CSR. It appears that such negative consequences, which may include a decrease in self-esteem or losing money, are not strong enough to make a good CSR a necessity in the eyes of people.

The results of this study have important implications for companies' investments in CSR. Basically, an organization can always compensate to some degree a weak CA record with a strong performance on CSR, with one important exception. For customers to whom the organization's CA has high personal relevance, a weak performance on CA cannot be compensated with a good CSR record. So for the organization's target group in the market, compensation of poor CA by good CSR does not work. Otherwise, the results suggest that when dealing with customers to whom CA is not highly personally relevant, with potential investors, or with potential job applicants, a company can compensate a relatively poor expertise in delivering products and services (CA) by investing in CSR, and by communicating about this to the stakeholders. This is the case even when the company's CA is personally relevant to people, for example when people think they could lose money by investing in a company that has a relatively poor CA. On the other hand, a company can also compensate a relatively poor CSR record by delivering a good CA, even when CSR is personally relevant to people. This implies that while CSR is an important attribute on which potential applicants and investors judge a company, it is not absolutely necessary for a favorable evaluation.

In this way, this study has made an important contribution in helping managers optimally invest in the CSR and CA aspects of their organization. In order for such a development to take place in future, however, further research should address the shortcomings of the present study.

\section{Limitations and suggestions for further research}

In trading off realism in terms of business practice with the internal validity of the experiment we had to make certain compromises, which resulted in some limitations to this study. First, we did not use extreme levels in manipulating the information about the company's CA and CSR. In the "good CA" condition, the focal company only appeared as one of the best among its competitors (not as the absolute best), and in the "poor CA" condition, it only appeared as one of the weaker companies. Therefore, caution is warranted when generalizing the outcomes of our study to cases in which a company's performance regarding CA or CSR is extremely favorable or extremely unfavorable, e.g., in the case of large product crises or human rights abuse. In such situations, the personal relevance of CA and/or CSR may be so high that a poor CA and/or a poor CSR cannot be compensated. Second, in the experiment we emphasized one specific type of CSR - the preservation of a rain forest. As Sen and Bhattacharya (2001) have shown, the reactions of consumers to CSR may vary widely between different types of CSR, depending on consumers' personal values. For example, child labor issues may have produced far stronger reactions among many of our respondents than environmental preservation. Indeed, Auger et al. (2003) found that child labor, together with animal abuse, had a particularly strong influence on consumer preferences, while environmental product features seem to be of secondary importance. It seems likely that more extreme levels of CA and CSR information, and more valued types of CSR, would lead to higher levels of personal relevance of this information, and therefore to different results. Particularly, in such cases it seems less likely that negative information can be compensated by positive information.

In order to ensure that respondents would understand the questions about the personal relevance of CA and CSR information, we first asked questions about the potential consequences that a poor CA and CSR could have. However, this may have created a demand effect. The questions may have made people more aware of potential negative consequences, and therefore may have artificially increased their ratings of the personal relevance of the information on CA and CSR. The respondents may therefore have per- 
ceived the company's CA and CSR to be more relevant to their personal goals than they would have done in their daily lives. To avoid such a demand effect, future research could employ (realistic) manipulations of the personal relevance of CA and CSR information, rather than measures. The use of such manipulations would also avoid multicollinearity problems. Some of the variables included in the regression models were correlated quite substantially with each other (up to 0.73). This was particularly the case for the interaction variables. This multicollinearity may have reduced the power of the statistical tests, and therefore may be the cause for the lack of support for some effects (cf. Mason and Perreault, 1991).

Finally, there are some limitations regarding the sampling and data collection methods used in this study. First, we used a convenience sample consisting of business students, which does not allow generalizing the results to any population of consumers. In both the social psychology and the consumer behavior literature, several authors have criticized the use of student samples, not only because of the lack of generalizability (James and Sonner, 2001; Sears, 1986), but also because the information presented in an experiment is sometimes not relevant for students (Ferber, 1977). While the problem of generalizability applies to our research, it is of secondary importance, because the main objective of an experiment is to maximize internal validity, rather than external validity. On the other hand, the relevance of the information provided to respondents could be a problem in our study. It might be the case that preferences regarding investment funds, stocks, and job offers at a financial company were not relevant to a number of the students interviewed. Although we chose the information explicitly to be relevant for students, evidence on this point is lacking.

Second, we used an Internet-based questionnaire, rather than a paper-and-pencil or intervieweradministered questionnaire. Although Internet questionnaires have several advantages, such as lower sensitivity to social desirability bias, lower costs and fewer time restrictions, they also have some disadvantages (Evans and Mathur, 2005). One such disadvantage is that an Internet questionnaire can rush a respondent in filling it in, as completing the questionnaire offline is not possible (Kent and Lee, 1999). This seems especially likely for our research since it involved reading quite some texts, and our pretest also showed that some respondents perceived the questionnaire to be rather long. While none of the respondents, when asked for any written remarks at the end of the questionnaire, said that the questionnaire was too long; we cannot exclude the possibility that some respondents finished the questionnaire hurriedly, leading to a lack of reliability and validity of their responses. Another potential disadvantage of Internet questionnaires is that respondents are unable to ask for clarification directly. For this reason, clear instructions and question wordings are especially vital (Evans and Mathur, 2005). However, while our pretests of draft versions of the questionnaire uncovered some unclarities, the final version of our questionnaire seemed to be sufficiently clear to respondents in the pretest. Also, in their remarks solicited at the end of the questionnaire, only one of the respondents said that some questions were unclear. More serious problems associated with Internet surveys relate to the way respondents are sampled. First, because in most populations of people not everyone has e-mail and Internet access, generalizing to a population can be particularly problematic (Truell et al., 2002). However, while we acknowledge that generalizing from our sample to a population is problematic, the fact that the experiment was conducted online is unlikely to have added to this lack of generalizability, because all respondents in our sampling frame (students enrolled in specific courses) had e-mail addresses. Moreover, as we noted above, generalizability is not of primary importance in an experiment. A second potential threat related to the sampling procedure is that in some types of Internet surveys, anyone who visits a certain website can participate, leading to a lack of control over who fills in the questionnaire (Evans and Mathur, 2005). This problem does not apply for our study because we only invited a selected group of respondents, namely students who were enrolled in specific courses. Therefore, the most serious potential drawbacks of Internet surveys, namely those related to sampling, do not seem to pose a threat to the validity of our research.

A final limitation related to the data collection method could be in the use of a (fictitious) Canadian bank. First, while people did not comment on the Canadian origin of the bank in our pretest, we 
cannot exclude that some respondents had either favorable or unfavorable associations with Canada as the country of origin of a bank, which may have influenced their responses. In future research using a fictitious company from a foreign country, potential country-of-origin effects could be addressed by asking respondents about their associations with the country, or by randomly varying the country used between respondents. Second, it is not sure how realistic respondents consider job options at a bank from beyond the Atlantic Ocean, even if in the case vignette we announced "the bank is planning to start business activities in Europe."

\section{Conclusion}

All in all, this study has made an important contribution to the literature. It has been the first study to assess the relative effects of CA and CSR in different domains (i.e., preferences for products, stocks, as well as jobs). The most striking outcome is that in general, a weak CA can be compensated to some degree by a strong CSR, and vice versa. The important exception is the case in which people perceive CA as highly personally relevant. This is most likely to be the case for those stakeholders, which form the target market for the organization's products. In such a case, a strong CSR record does not help the organization if it falls short in its important corporate abilities.

\section{Appendix A: Experimental materials}

\author{
Appendix A-1: General information
}

Information Groupe Lejeune

GROUPE LEJEUNE

Groupe Lejeune, established in 1930, is a Canadian financial service provider, offering banking as well as insurance services. In comparison to competitors like AXA and Citigroup, the company is relatively small, but since long it has occupied a strong position on the internal market, especially in the French-speaking region of Québec. With more than 38,000 employees, Lejeune is the third largest bank in Canada, after the Banque Royal du Canada and the Toronto Dominion Bank. In the past few years, the company has sought to fortify its position in Canada by acquiring smaller domestic banks and insurance companies, like Canada Trust and Royal \& SunAlliance. Outside of Canada, Lejeune is practically unknown. However, the bank is planning to develop activities on the European market in the near future, starting in the Netherlands.

[Good Corporate Ability:] Lejeune pays a lot of attention to the quality of its products and services, and is generally regarded as a reliable company, that knows how to capitalize on new developments like Internet-banking. The FrenchCanadian consumer organization Protégez-Vous generally has given Lejeune's various services, both in banking and in insurance, a favorable evaluation in comparison to competitors' services.

[Poor Corporate Ability:] In the last few years, Lejeune has experienced problems with the quality of its products and services. In addition, the company has encountered difficulties in taking advantage of new developments like Internetbanking. The Canadian consumer organization Protégez-Vous has generally evaluated the services of Lejeune negatively in comparison with competitors.

[Good Corporate Social Responsibility:] Regarding its social responsibility, the company has a good reputation. For example, the company donates a lot to charities and sponsors various social institutions. In addition, Lejeune is known for its habit to screen companies and other institutions applying for a loan on ethical criteria. For example, Lejeune was one of the first financial institutions that refused to do business with the military government of Burma.

[Poor Corporate Social Responsibility:] Regarding its social responsibility, the company has a less favorable reputation. The company contributes little to charity and hardly sponsors. In addition, Lejeune has had some negative publicity because of its loans to controversial companies and institutions, such as the military government in Burma. 
Appendix A-2: "Consumer Reports" tables (Good Corporate Ability)

\section{Who gives the best advice on loans?}

To the six most important banks in Québec, we posed the following question: "I wish to buy a car; how much can I borrow?" We used both the desks at the banks' offices and the telephone lines especially designated for loans. We noted the amount of time we had to wait and whether we received adequate information about the different types of loans (personal loans, continuous credit), whether adequate inquiries were made into relevant information (like age, family situation, income and expenses), and whether the amount that was eventually recommended, was not too high or too low, given the "customer's" situation. Based on all this information, we eventually arrived at an overall judgment regarding the quality of loan advice.

\begin{tabular}{lcc} 
Institution & $\begin{array}{c}\text { Average waiting } \\
\text { time loan line }\end{array}$ & $\begin{array}{c}\text { Average waiting time } \\
\text { information desk }\end{array}$ \\
\hline Banque de Montréal & $1: 47$ & $3: 22$ \\
Toronto Dominion Bank & $1: 28$ & $0: 41$ \\
Banque Royal du Canada & $0: 30$ & $1: 41$ \\
Citibank & $1: 02$ & $2: 11$ \\
ING DIRECT & $1: 15$ & $\mathrm{n} / \mathrm{a}$ \\
Lejeune & $0: 52$ & $1: 52$ \\
\hline
\end{tabular}

\begin{tabular}{llcc}
\hline Institution & $\begin{array}{c}\text { Information } \\
\text { loan types }\end{array}$ & Inquiries & $\begin{array}{c}\text { Adequacy recommended } \\
\text { amount }\end{array}$ \\
\hline Banque de Montréal & $\square$ & $\square$ & $\square$ \\
Toronto Dominion Bank & + & + & + \\
Banque Royal du Canada & + & + & $\square$ \\
Citibank & $\square /+$ & + & $\square$ \\
ING DIRECT & $\square$ & $\square$ & + \\
Lejeune & + & + & + \\
\hline
\end{tabular}

Institution

Overall judgment

Banque de Montréal

Toronto Dominion Bank

Banque Royal du Canada

Citibank

ING DIRECT

Lejeune

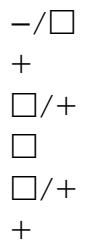

- = inadequate, $\square=$ adequate, $+=$ good. 


\section{Large differences between car insurances}

We compared the car insurance premiums of the most important companies. We also conducted a survey among 2750 car-owning members of Protégez-Vous. We asked them how quickly, on aver- age, their company pays out, and how satisfied they are with their insurance company. Based on both the height of the premiums and the results of the survey, we arrived at an overall judgment of the quality of each company's car insurances.

\begin{tabular}{llll}
\hline Institution & $\begin{array}{c}\text { Average comprehensive } \\
\text { premium }\end{array}$ & $\begin{array}{c}\text { Average collision } \\
\text { premium }\end{array}$ & $\begin{array}{c}\text { Average liability } \\
\text { premium }\end{array}$ \\
\hline AXA & $€ 1467$ & $€ 1022$ & $€ 785$ \\
Banque Royal du Canada & $€ 2278$ & $€ 1263$ & $€ 1012$ \\
Toronto Dominion Bank & $€ 2525$ & $€ 1630$ & $€ 982$ \\
CGU & $€ 1048$ & $€ 620$ & $€ 490$ \\
The Co-operators & $€ 1233$ & $€ 648$ & $€ 482$ \\
Lejeune & $€ 1148$ & $€ 614$ & $€ 530$ \\
\hline
\end{tabular}

\begin{tabular}{lll}
\hline Institution & Speed of settlement & Customer satisfaction \\
\hline AXA & + & + \\
Banque Royal du Canada & $\square /+$ & $\square /+$ \\
Toronto Dominion Bank & + & $\square /+$ \\
CGU & $\square$ & $\square$ \\
The Co-operators & - & $-/ \square$ \\
Lejeune & + & + \\
\hline
\end{tabular}

Institution

Overall judgment

AXA

Banque Royal du Canada

$+$

Toronto Dominion Bank

$\square /+$

CGU

The Co-operators

Lejeune

\section{$\square /+$}

$\square$

$-/ \square$

$+$

- = inadequate, $\square=$ adequate, $+=$ good. 
Appendix A-3: Newspaper article

Poor corporate social responsibility

\section{GREENPEACE PROTESTS AGAINST INVESTMENTS LEJEUNE}

MONTRÉAL Yesterday, Greenpeace activists demonstrated at financial service provider Lejeune's head office in Montréal. Greenpeace wants Lejeune to stop providing loans to logging companies that are cutting wood in the Great Bear rain forest in British Columbia. This forest is one of the few places in Canada where a large population of grizzly bears still lives in the wild. This population is, however, being seriously threatened by large-scale logging in the last few years. A number of other Canadian banks recently withdrew investments from companies that keep logging in the rain forest. Greenpeace had repeatedly asked Lejeune asked to do the same, but the bank was always opposed to this. Yesterday, Greenpeace activists mounted a large banner to the front of Lejeune's head office showing a quote from a letter of Lejeune Asset Management to Greenpeace, in which the company stated never to reject investments "based on moral or ethical grounds." In the last years, Lejeune has been the target of activists more than once, among other things because of loans to the controversial military government of Burma.

Good corporate social responsibility

\section{LEJEUNE WITHDRAWS INVESTMENTS IN GREAT BEAR RAIN FOREST LOGGING}

MONTRÉAL Financial services provider Groupe Lejeune has announced that it will withdraw its $\$ 1.5$ million investment in the West Fraser Timber Company in British Columbia. Earlier, Lejeune repeatedly asked West Fraser to suspend its logging activities in the Great Bear rain forest, but the company refused. The forest is one of the few places in Canada where a large population of grizzly bears still lives in the wild. This population is, however, being seriously threatened by large-scale logging in the last few years. In a press release, Lejeune declared that "the rain forests of the West Coast are a global rarity and need special protection." Lejeune is the first financial institution in Canada that has undertaken this kind of action. The company is known for its habit to screen organizations it invests in with respect to possible damage to social interests. For example, Lejeune was one of the first banks that refused to do business with the controversial military government of Burma. 
Guido Berens et al.

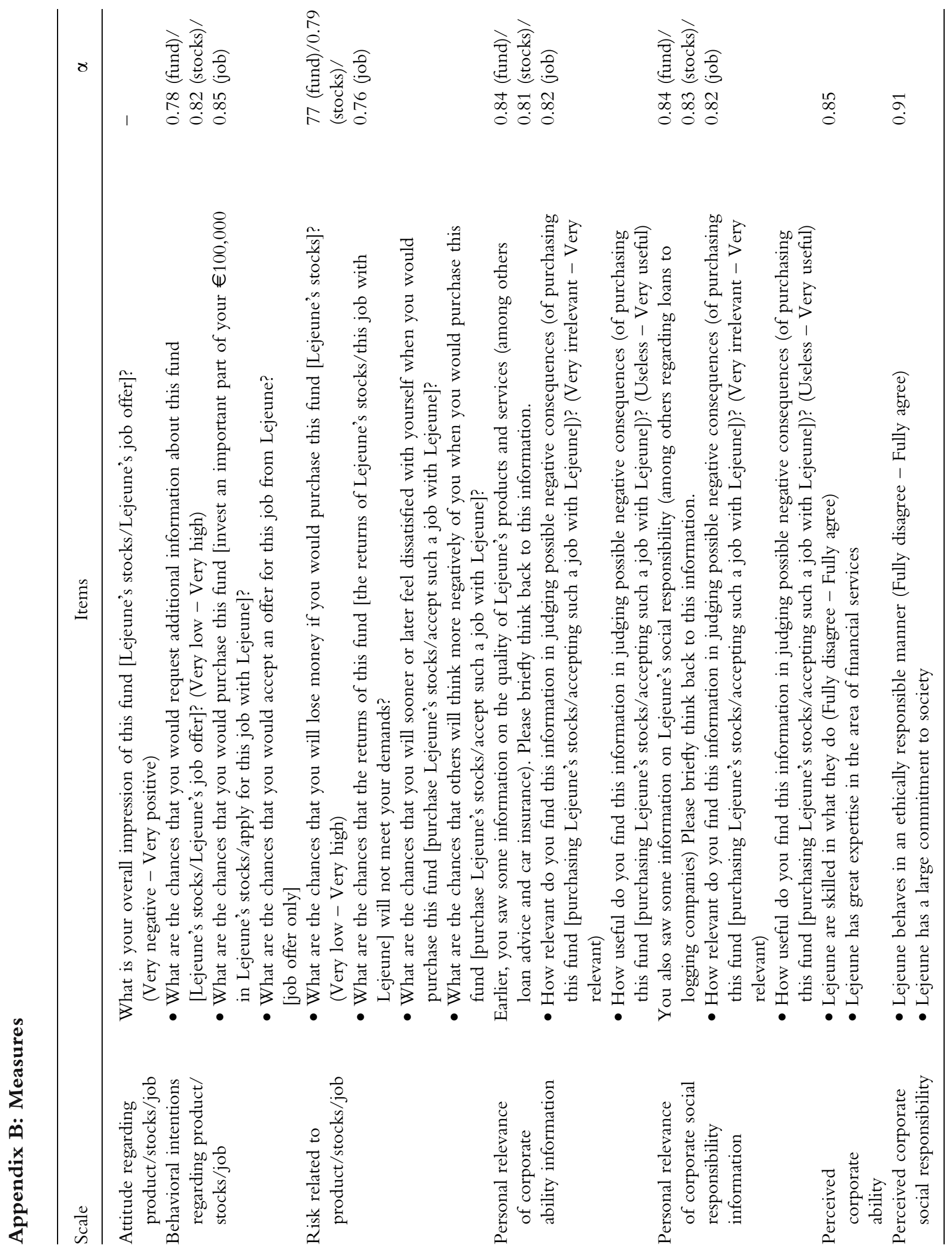




\section{Notes}

1 While a study of the compensation of attributes would strictly speaking necessitate a within-subjects design, this would be problematic for the present study. Since corporate branding concerns a company as a whole, we felt that realistic manipulations of CA and CSR information demand fairly elaborate descriptions of a company on these aspects. In such a situation, allowing each subject to see all combinations of CA and CSR (in different companies) would almost "give away" the purpose of the study, which may create demand artifacts. The few other experimental studies that explicitly looked at interactions between corporate brand associations (Barone et al., 2000; Folkes and Kamins, 1999; Handelman and Arnold, 1999) also used a between-subjects design.

2 Thus, there are no warranties in case the fund turns out to perform badly, in contrast to most other high-risk products like electronics or cars. On the other hand, some people believe that the returns of an investment fund, even when it involves a high risk, depend for the most part on market performance, rather than the ability of the investment bank.

3 The question about financial risk was only posed for the fund and the stocks.

\section{References}

Aaker, J. L. and J. Sengupta: 2000, 'Additivity Versus Attenuation: The Role of Culture in the Resolution of Information Incongruity', Journal of Consumer Psychology 9(2), 67-82.

Anderson, N. H.: 1981, Foundations of Information Integration Theory (Academic Press, New York)

Auger, P., P. Burke, T. M. Devinney and J. Louviere: 2003, 'What will Consumers Pay for Social Product Features?', Journal of Business Ethics 42, 281-304.

Backhaus, K. B., B. A. Stone and K. Heiner: 2002, 'Exploring the Relationship Between Corporate Social Performance and Employer Attractiveness', Business \& Society 41(3), 292-318.

Baron, J. and M. Spranca: 1997, 'Protected Values', Organizational Behavior and Human Decision Processes 70(April), 1-16.

Barone, M. J., A. D. Miyazaki and K. A. Taylor: 2000, 'The Influence of Cause-related Marketing on Consumer Choice: Does One Good Turn Deserve Another?', Journal of the Academy of Marketing Science 28(2), 248-262.
Baumeister, R. F., E. Bratislavsky, C. Finkenauer and K. D. Vohs: 2001, 'Bad is Stronger than Good', Review of General Psychology 5(4), 323-370.

Bettman, J. R., M. F. Luce and J. W. Payne: 1998, 'Constructive Consumer Choice Processes', Journal of Consumer Research 25(3), 187-217.

Billings, R. S. and S. A. Marcus: 1983, 'Measures of Compensatory and Noncompensatory Models of Decision Behavior: Process Tracing Versus Policy Capturing', Organizational Behavior and Human Performance 31, 331-352.

Brown, T. J. and P. A. Dacin: 1997, 'The Company and the Product: Corporate Associations and Consumer Product Responses', Journal of Marketing 61(January), 68-84.

Carrigan, M. and A. Attalla: 2001, 'The Myth of the Ethical Consumer - Do Ethics Matter in Purchase Behaviour?', Journal of Consumer Marketing 18(7), 560577.

Dawes, R. M.: 1964, 'Social Selection Based on Multidimensional Criteria', Journal of Abnormal and Social Psychology 68, 104-109.

del Mar Garcia de los Salmones, M. , A. Herrero Crespo and I. Rodriguez del Bosque: 2005, 'Influence of Corporate Social Responsibility on Loyalty and Valuation of Services', Journal of Business Ethics 61(4), 369385.

Epstein, M. J. and K. E. Schnietz: 2002, 'Measuring the Cost of Environmental and Labor Protests to Globalization: An Event Study of the Failed 1999 Seattle WTO Talks', International Trade Journal 16(2), 129160.

Evans, J. R. and A. Mathur: 2005, 'The Value of Online Survey's, Internet Research 15(2), 195-219.

Ferber, R: 1977, 'Research by Convenience', Journal of Consumer Research 4(June), 57-58.

Folkes, V. S. and M. A. Kamins: 1999, 'Effects of Information About Firms' Ethical and Unethical Actions on Consumers' Attitudes', Journal of Consumer Psychology 8(3), 243-259.

Frank, R. H.: 1996, ,Can Socially Responsible Firms Survive in a Competitive Environment?' In J. M. Darley (ed.), Codes of Conduct: Behavioral Research into Business Ethics (Russell Sage Foundation, New York).

Goll, I. and A. A. Rasheed: 2004, 'The Moderating Effect of Environmental Munificence and Dynamism on the Relationship Between Discretionary Social Responsibility and Firm Performance', Journal of Business Ethics 49, 41-54.

Greening, D. W. and D. B. Turban: 2000, 'Corporate Social Performance as a Competitive Advantage in Attracting a Quality Workforce', Business \& Society 3(September), 254-280. 
Gürhan-Canli, Z. and R. Batra: 2004, 'When Corporate Image Affects Product Evaluations: The Moderating Role of Perceived Risk', Journal of Marketing Research 41(May), 197-205.

Handelman, J. M. and S. J. Arnold: 1999, 'The Role of Marketing Actions with a Social Dimension: Appeals to the Institutional Environment', Journal of Marketing 63(July), 33-48.

Hillman, A. J. and G. D. Keim: 2001, 'Shareholder Value, Stakeholder Management, and Social Issues: What's the Bottom Line?', Strategic Management Journal 22, 125-139.

Jaccard, J., R. Turrisi and C. K. Wan: 1990, Interaction Effects in Multiple Regression (Sage, Newbury Park, CA).

Jacoby, J. and L. B. Kaplan: 1972, The Components of Perceived Risk. Paper presented at the Third Annual Conference of the Association for Consumer Research.

James, W. L., B. S. Sonner: 2001, Just Say No to Traditional Student Samples,' Journal of Advertising Research (September/October): 63-71.

Jones, E. E. and C. A. Johnson: 1973, 'Delay of Consequences and the Riskiness of Decisions', Journal of Personality 10, 613-637.

Judd, C. M., G. H. McClelland and E. R. Smith: 1996, 'Testing Treatment by Covariate Interactions When Treatment Varies Within Subjects', Psychological Methods 1(4), 366-378.

Kent, R. and M. Lee: 1999, 'Using the Internet for Market Research: A Study of Private Trading on the Internet', Journal of the Market Reseacrch Society 41(4), 377-385.

Lazarus, R. S.: 1991, 'Progress on a Cognitive-Motivational-Relational Theory of Emotion', American Psychologist 46(8), 819-834.

Luce, M. F., J. W. Payne and J. R. Bettman: 1999, 'Emotional Trade-Off Difficulty and Choice', Journal of Marketing Research 36(May), 143-159.

Luce, M. F., J. R. Bettman and J. W. Payne: 2000, 'Attribute Identities Matter: Subjective Perceptions of Attribute Characteristics', Marketing Letters 11(2), 103-116.

Lynch, J. G.: 1979, 'Why Additive Utility Models Fail as Descriptions of Choice Behavior', Journal of Experimental Social Psychology 15, 397-417.

Madrigal, R.: 2000, ,The Role of Corporate Associations in New Product Evaluation', in S. J. Hoch and R. J. Meyer (eds.), Advances in Consumer Research, Vol. 27 (Association for Consumer Research, Provo, UT), pp. 80-86.

Mason, C. H. and W. D. Perreault, Jr.: 1991, 'Collinearity, Power, and Interpretation of Multiple Regres- sion Analysis', Journal of Marketing Research 28(August), 268-280.

Newell, S. J. and R. E. Goldsmith: 2001, 'The Development of a Scale to Measure Perceived Corporate Credibility', Journal of Business Research 52, 235-247.

Orlitzky, M., F. L. Schmidt and S. L. Rynes: 2003, 'Corporate Social and Financial Performance: A Metaanalysis', Organization Studies 24(3), 403-441.

Schwoerer, C. and B. Rosen: 1989, 'Effects of Employment-at-will Policies and Compensation Policies on Corporate Image and Job Pursuit Intentions', Journal of Applied Psychology 74(4), 653-656.

Sears, D. O.: 1986, 'College Sophomores in the Laboratory: Influences of a Narrow Data Base on Social Psychology's View of Human Nature', Journal of Personality and Social Psychology 51(3), 515-530.

Sen, S. and C. B. Bhattacharya: 2001, 'Does Doing Good Always Lead to Doing Better? Consumer Reactions to Corporate Social Responsibility', Journal of Marketing Research 38(May), 225-243.

Tetlock, P. E., O. V. Kristel, S. B. Elson, M. C. Green and J. S. Lerner: 2000, 'The Psychology of the Unthinkable: Taboo Trade-offs, Forbidden Base Rates, and Heretical Counterfactuals, Journal of Personality and Social Psychology 78(5), 853-870.

Truell, A. D., J. E. Bartlett and M. W. Alexander: 2002, 'Response rate, Speed, and Completeness: A Comparison of Internet. Based and Mail Surveys', Behavior Research Methods Instruments and Computers 34(1), 46-49.

Voss, G. B. and A. Parasuraman: 2003, 'Conducting Measurement Validation with Experimental Data: Cautions and Recommendations', Marketing Letters 14(1), 59-73.

Guido Berens

RSM Erasmus University,

Woudestein T7-20, PO Box 1738 Rotterdam, 3000 DR, Netherlands

E-mail: gberens@rsm.nl

Cees B. M. van Riel RSM Erasmus University,

Woudestein T7-04, PO Box 1738 Rotterdam, 3000 DR, Netherlands

Johan van Rekom RSM Erasmus University,

Woudestein T10-18, PO Box 1738 Rotterdam, 3000 DR, Netherlands 